\title{
Sources of variance and reliability of objectively monitored physical activity in rural and urban Northern Sotho-speaking blacks
}

\author{
Ian Cook (BA (Phys Ed) Hons, BSc (Med) Hons) ${ }^{1}$ \\ Estelle V Lambert $(\mathrm{PhD})^{2}$ \\ ${ }^{1}$ Physical Activity Epidemiology Laboratory, University of Limpopo (Turfloop Campus), South Africa \\ ${ }^{2}$ MRC/UCT Research Unit for Exercise Science and Sports Medicine, University of Cape Town Medical School, South Africa
}

\begin{abstract}
Objectives. We investigated the sources of variance and reliability in an objective measure of physical activity for a 14 hour and 4-day monitoring period.

Design. A convenience sample of rural $(N=31)$ and urban $(N=30)$ adult, Northern Sotho-speaking blacks was recruited. Physical activity was assessed for 8 consecutive days using a uni-axial accelerometer. Physical activity indices were total counts, average counts, inactivity ( $<500$ counts) moderate1 activity (500 - 1951 counts), moderate-2+vigorous activity ( $\geq 1952$ counts), and were expressed per hour or per day as required.
\end{abstract}

Results. Accelerometry data from 41 subjects (23 males, 18 females) complied with selection requirements and were analysed for variance distribution and reliability (intraclass correlation coefficients (ICCs)). For the 14-hour monitoring period variance was distributed as follows: intra-individual (71 - $82 \%)$, inter-individual (3 - 18\%) and hour-of-day (2 - 14\%). Attenuated ICCs ranged from 0.31 to 0.75 (median: 0.70 ). Variance for the 4-day monitoring period differed from the 14-hour monitoring period: inter-individual (47 - 58\%), intraindividual (43 - 51\%) and day-of-week (0 - 6.5\%). Attenuated ICCs ranged from 0.27 to 0.84 (median: 0.79 ). Irrespective of the monitoring period, total counts, average counts and moderate-2+vigorous activity tended to be the most reliable measures requiring the fewest number of monitoring periods.

Conclusions. These findings provide an insight for understanding how variance is distributed in objectively measured activity patterns of a South African sample and show that reli-

\section{CORRESPONDENCE:}

lan Cook

Physical Activity Epidemiology Laboratory

University of Limpopo (Turfloop Campus)

PO Box 459

Fauna Park

0787 Polokwane

South Africa

Tel+fax: +27152682390

E-mail: ianc@ul.ac.za able measures of adult physical activity behaviours require 18 - 128 hours and 3 - 44 days, depending on the monitoring period, physical activity index, residence status and sex.

\section{Introduction}

Human movement and the concomitant increase in energy expenditure are fundamental aspects of human existence. The importance of movement-related energy expenditure has been acknowledged since antiquity but has only relatively recently seen substantial research activity. ${ }^{7}$ Arguably, the dramatic global increase in chronic diseases of lifestyle over the last century has spurred the interest in exploring the importance of human energy expenditure in relation to health ${ }^{7}$ and has led to evidence-based public health guidelines for health-enhancing physical activity. ${ }^{13}$

A number of instruments are available for estimating human energy expenditure and range from paper and pencil methods to doubly-labelled water. ${ }^{20,28}$ Irrespective of the method employed, it is important that the sources and magnitude of the variability of physical activity are quantified so that research activities in physical activity and health are appropriately designed, analysed and interpreted. ${ }^{28}$ By partitioning physical activity variability into discrete components, the number of periods of monitoring required to reliably estimate physical activity volumes and patterns of individuals in a population can be determined. ${ }^{28}$ Importantly, the number of periods of monitoring will influence aspects of study design such as sample size and statistical power. ${ }^{28}$ It should be noted that assessments of energy intake (diet) and energy expenditure (physical activity) are susceptible to the same types of measurement error. ${ }^{16}$

Numerous studies in industrialised countries have investigated the reliability of objectively monitored freeliving physical activity. 3,8-11,14-16,21,24-27 However, few papers have reported sources of variation for either physical activity questionnaires $^{14,17,18}$ or objectively monitored physical activity. ${ }^{15}$ Within the South African context there is a dearth of reliability studies for any form of physical activity assessment. ${ }^{2,4,5,12}$ The reliability of objectively monitored free-living physical activity in South African samples has not been reported. Moreover, no data have been reported regarding the sources of variation for any type of physical activity measurement instrument in South African samples. From a regional and international perspective, we are not aware of any data from sub-Saharan Africa or any developing 
country that have addressed variance distribution and reliability of objectively monitored free-living physical activity.

Reliability and variance distribution have been widely investigated within nutritional epidemiology $y^{22,23,29}$ but less so in physical activity measures that are often used to estimate physical activity patterns and energy expenditure. ${ }^{28}$ This is probably because of the relatively recent emergence of a new branch of epidemiology, namely physical activity epidemiology. ${ }^{7}$ Considering the heterogeneity of the South African population, studies investigating the variance distribution and reliability of physical activity assessments across sub-sections of the South African population are required.

The objective of this paper was firstly to investigate the sources and distribution of variance for objectively measured physical activity over a number of hours and days in a sample of rural and urban Northern Sotho-speaking blacks. The second objective was to determine the number of hours and days required to reliably measure 1 hour and 1 day of accelerometerderived indices of physical activity in this particular South African sample.

\section{Methods}

\section{Study protocol}

The data used in this analysis were collected during the validity trial of the International Physical Activity Questionnaire (IPAQ) which has been reported elsewhere. ${ }^{2,5}$ For this analysis only the accelerometer data were considered. Briefly, black Northern Sotho-speaking rural and urban participants were recruited and contacted twice over an 8-day period. On the first occasion, subjects were recruited, completed a socio-demographic questionnaire and provided anthropometric data. All interviews and anthropometric measures were conducted by trained black male and female field workers. Anthropometric measures included body mass $(\mathrm{kg})$ and stature $(\mathrm{cm})$ allowing the calculation of body mass index (BMI, kg.m $\left.{ }^{-2}\right)$. Finally, subjects were instructed on the necessary procedures for wearing the accelerometer. Eight days later the accelerometers were collected. Subjects received a small honorarium on completion of the study. Signed informed consent was obtained from all participants. The study was approved by the Ethics Committee of the University of Limpopo (Turfloop Campus).

\section{Subjects}

\section{Rural sample}

A convenience sample of black employees, resident on farms and villages, were recruited from the plantation section of a local lumber mill situated in the Limpopo Province, South Africa (total $N=31$, males $N=18$, females $N=13$ ). These workers performed a variety of manual tasks and ensured that plantations were created and maintained, and that raw timber was harvested, sized, cleaned and stacked prior to transport to the saw mill for further processing.

\section{Urban sample}

A convenience sample was recruited from black academic staff, support staff and students of the University of the Limpopo (Turfloop Campus), and black residents (office workers, teachers) from the surrounding community (Mankweng) and nearby city
(Polokwane) (total $N=30$, males $N=14$, females $N=16$ ). For the most part, these subjects performed tasks typical of office workers, with long periods of sedentary activity (sitting, standing quietly).

\section{Physical activity counts and durations}

To objectively quantify free-living physical activity of the subjects, uni-axial accelerometers were worn for at least 8 days. The CSA model 7164 (Computer Science Applications, Inc. Shalimar, FL), now marketed as the MTI Actigraph (MTI Health Services, Fort Walton Beach, $\mathrm{FL})$, is small and unobtrusive $(5.1 \mathrm{~cm} \times 4.1 \mathrm{~cm}$ x $1.5 \mathrm{~cm}, 42.6 \mathrm{~g}) .{ }^{28}$ In this study, the epoch duration was set at 1 minute. The accelerometer was worn on the right waist, securely attached to a nylon belt. The accelerometers could be removed for sleeping and bathing purposes by unclipping the nylon belt. The data were downloaded from the accelerometers onto an IBM-compatible personal computer via an interface unit, for further analysis using CSA-supplied software (DAYBYDAY. XLS, Microsoft Excel@97 macro) and a customised data reduction programme (Microsoft Excel@97 macro). Physical activity counts were defined as total counts (counts.day ${ }^{-1}$ ) and average counts (counts.min-1.day ${ }^{-1}$ ). Physical activity intensity patterns or durations (min.day ${ }^{-1}$ ) of inactivity and moderate and vigorous activity were created according to cut-points defined by Matthews et al. ${ }^{15}$ Inactivity (sitting, standing quietly) was defined as less than 500 counts. min $^{-1}$. For moderate activity (3-6 METs, $1 \mathrm{MET}=1$ metabolic equivalent $=3.5 \mathrm{mlO}_{2} \cdot \mathrm{kg}^{-1} \cdot \mathrm{min}^{-1}=1$ $\mathrm{kcal} . \mathrm{kg}^{-1} \cdot \mathrm{hr}^{-1}$ ) a distinction was made between activities requiring less ambulation (moderate-1: house work, yard work) and predominantly ambulatory activities (moderate-2: walking). The cut-points for moderate- 1 and moderate- 2 were defined as 500 - 1591 counts. min $^{-1}$ and 1592 - 5724 counts. min $^{-1}$, respectively. Activities, such as running, which record more than 5724 counts. min $^{-1}$ were defined as vigorous ( $>6 \mathrm{METs}$ ).

The first and last days of the 8-day monitoring period were excluded. To evaluate the number of hours required to reliably estimate 1 hour of objectively monitored physical activity, the first weekday with at least 14 hours of registration (06h00 to $20 \mathrm{~h} 00$ ) was selected. To evaluate the number of days required to reliably estimate 1 day of objectively monitored physical activity, accelerometer data for 4 days ( 3 weekdays and 1 weekend day) were used. Only days with at least 10 hours. day ${ }^{-1}(600$ minutes. day $^{-1}$ ) of registration were included. ${ }^{5}$ From the minute-by-minute data, hourly and daily accelerometry indices were summed (counts.hour $^{-1}$, counts.day ${ }^{-1}$, minutes.hour ${ }^{-1}$, minutes.day ${ }^{-1}$ ). Accelerometry data of 41 subjects ( 23 males, 18 females) which constituted $67.2 \%$ of the original sample of 61 , complied with all the selection criteria.

\section{Statistical analysis}

The descriptive analysis comprised residence-specific means and standard deviations and percentages for continuous and categorical variables, respectively. For skewed continuous accelerometry variables ( $\geq 2 x$ standard deviation), residence-specific medians and interquartile ranges were calculated. Differences (rural v. urban) between two independent categorical variables were tested for significance (with continuity correction for small sample sizes). ${ }^{1}$ To examine differences (rural v. urban) between two independent continuous variables, an independent t-test was used. Because the distributions of some variables were neither normal nor lognormal a comparable non-parametric test was used (Mann-Whitney U test). 
Hourly (14 hours) and daily (4 day) accelerometry indices were rank transformed because the distributions of several residencespecific accelerometer indices were neither normal nor lognormal. To evaluate the sources of variability in ranked accelerometer data, variance components in mixed and random effects models were estimated using restricted maximum likelihood methods. ${ }^{15}$ Accelerometer indices were the dependant variables for these analyses. Variance components were estimated for subject (interindividual) variance, trial (hour or day) variance, and residual (intra-individual) variance. The variance components were also expressed as a percentage of the total variance. Inter-individual variance represents true variation between subjects while intraindividual variance represents hour-to-hour or day-to-day variation within subjects. The variance due to the hour or day effect was nested within subjects. To identify variables that could affect the inter-individual variance and thus the reliability we entered age, body mass index, educational level, residence (rural/urban) and sex (male/female) individually as fixed factors. From this preliminary analysis (data not shown) we identified residence and sex as having the most consistent and substantial impact on interindividual variance. The first analysis was conducted on the whole sample such that variance components for subject, trial (day or

\section{TABLE I. Descriptive characteristics for rural and urban subjects}

\begin{tabular}{|c|c|c|c|}
\hline & & Residence & \\
\hline & Rural & Urban & $p^{\ddagger}$ \\
\hline Continuous variables & $(N=21)$ & $(N=20)$ & \\
\hline Age (years) & $38.9(10.4)$ & $32.9(6.7)$ & 0.037 \\
\hline BMI $\left(\mathrm{kg} \cdot \mathrm{m}^{-2}\right)$ & $22.9(3.9)$ & $27.2(5.3)$ & 0.006 \\
\hline Accelerometer data (4-day average) & & & \\
\hline Activity counts (cts) & & & \\
\hline Total counts (cts.day ${ }^{-1}$ ) & $644102(208420)$ & 409341 (169 799) & 0.001 \\
\hline Average counts (cts.min-1.day ${ }^{-1}$ ) & $847(267)$ & $618(248)$ & 0.008 \\
\hline Duration (min.day ${ }^{-1}$ ) & & & \\
\hline Inactivity (0 - 499 cts) & $1078(92)$ & $1236(58)$ & $<0.001$ \\
\hline Moderate 1 (500 - $1951 \mathrm{cts})$ & $265(67)$ & $141(35)$ & $<0.001$ \\
\hline Moderate 2 - vigorous (>1951 cts) * & $94(55)$ & $51(65)$ & 0.027 \\
\hline Categorical variables $^{\dagger}$ & & & \\
\hline Body mass index classification & & & \\
\hline Normal weight $\left(<25 \mathrm{~kg} \cdot \mathrm{m}^{-2}\right)$ & $76.2(16)$ & $40.0(8)$ & 0.042 \\
\hline Overweight to obese ( $\geq 25 \mathrm{~kg} \cdot \mathrm{m}^{-2}$ ) & $23.8(5)$ & $60.0(12)$ & 0.042 \\
\hline Female participants & $47.6(10)$ & $40.0(8)$ & 0.860 \\
\hline Education ( $\geq$ grade 12) & $0(0)$ & $85.0(17)$ & $<0.001$ \\
\hline Ownership of motor vehicle (yes) & $14.3(3)$ & $40.0(8)$ & 0.132 \\
\hline Electricity available inside house (yes) & $19.0(4)$ & 85.0 (17) & $<0.001$ \\
\hline
\end{tabular}

TABLE II. Crude and adjusted intra- to inter-subject variance ratios $\left(\sigma^{2}{ }_{w} / \sigma_{B}^{2}\right)$ by monitoring period

\begin{tabular}{|c|c|c|c|c|}
\hline & & & $\sigma^{2}{ }_{w} / \sigma^{2}{ }_{\text {B rat }}$ & \\
\hline & Variables ${ }^{*}$ & Crude $^{\dagger}$ & Adjusted $^{\ddagger}$ & $\%$ Change $^{\S}$ \\
\hline 14-Hours $(N=41)$ & Total counts & 3.44 & 7.06 & 105.0 \\
\hline & Average counts & 3.80 & 7.29 & 91.6 \\
\hline & Inactivity & 3.09 & 9.07 & 193.2 \\
\hline & Moderate-1 & 2.75 & 11.34 & 312.8 \\
\hline & Moderate-2+vigorous & 3.41 & 5.35 & 56.9 \\
\hline 4-Days $(N=41)$ & Total counts & 0.66 & 1.01 & 53.6 \\
\hline & Average counts & 0.55 & 0.73 & 33.6 \\
\hline & Inactivity & 0.58 & 1.53 & 163.0 \\
\hline & Moderate-1 & 0.67 & 2.49 & 269.9 \\
\hline & Moderate-2+vigorous & 0.77 & 1.04 & 35.6 \\
\hline
\end{tabular}


hour) and residual were extracted with and without adjustment for fixed effects of residence and sex. From the extracted variance components, intra- to inter-subject variance ratios $\left(\sigma^{2}{ }_{w} / \sigma^{2}{ }_{B}\right)$ were calculated, where $\sigma_{\mathrm{B}}^{2}$ was the between or inter-individual variance and $\sigma_{w}^{2}$ was the within- or intra-individual variance. To examine possible differences in the distribution of variance (inter-individual, hour or day effect, residual) across residence status, the second analysis was stratified by residence while treating sex as a fixed factor.

Reliability coefficients were calculated from the variance components extracted from the residence-stratified variance component analysis, with sex treated as a fixed factor. Reliability was calculated as an average measure $\left(\mathrm{ICC}_{\mathrm{M}}\right)$ and a single measure (ICCS) intraclass correlation coefficient (ICC) using the following equations, $I C C_{M}=\sigma_{B}^{2} /\left(\sigma_{B}^{2}+\sigma^{2}{ }_{w}\right)$ and ICC $C_{S}=\sigma_{B}^{2} /$ $\left(\sigma^{2}{ }_{B}+\sigma^{2}{ }_{w} / k\right)$, where $\sigma_{B}^{2}$ was the inter-individual variance, $\sigma^{2}{ }_{W}$ was the intra-individual variance and $k$ was the number of days or hours. ${ }^{19}$ Because unbounded, ranked data were used to obtain an ICC from a model meant for continuous data, ${ }^{6}$ the corrected and uncorrected $\mathrm{ICC}_{\mathrm{M}}$ from the mean squares of an ANOVA-based variance component analysis were also calculated. ${ }^{19}$ There was no difference in $\mathrm{ICC}_{\mathrm{M}}$ after the correction (data not shown).

Deattenuated 4-day and 14-hour $\mathrm{ICC}_{\mathrm{m}}$ were calculated using the formula, ICC true $=I C C_{\text {obs }} \times\left(1+\left[\sigma^{2}{ }_{\mathrm{w}} / \sigma^{2}{ }_{\mathrm{B}}\right] / k\right){ }^{0.5}$ where $I C C_{\text {true }}$ was the true correlation, $I C C_{\text {obs }}$ was the observed correlation, $\sigma^{2}{ }_{w}$ was the intra-individual variance, $\sigma^{2}$ B was the inter-individual variance and $k$ the number of monitoring periods. ${ }^{16,28}$ Because random variation (intra-individual variance) reduces the ability to identify significant effects, deattenuation is employed to adjust for random variation such that a better estimate is obtained of the true statistic. To estimate the number of hours and days required to reliably predict 1 hour and 1 day of accelerometry, respectively, the following equation was rearranged to solve for $k$, ICC $=\sigma^{2}{ }_{B} /\left(\sigma_{B}^{2}\right.$ $\left.+\sigma^{2}{ }_{w} / k\right)$ were ICC $=0.80$. Data were analysed using appropriate statistical software (SPSS for Windows 11.0.1). Significance for all inferential statistics was set at $p<0.05$.

\section{Results}

Subject characteristics are reported in Table I. Because of the relatively low volume and highly skewed distribution of the recorded vigorous activity (rural: $3.7 \pm 6.7 \mathrm{~min}$ v. urban: $3.2 \pm 5.3 \mathrm{~min}$ ), the moderate- 2 and vigorous variables were combined. Significant differences were found between rural and urban groups for all continuous and categorical variables, except for sex distribution and vehicle ownership. Of note were the significantly lower levels of obesity and inactivity, and greater levels of activity in the rural group compared with the urban group.

Crude and adjusted variability ratios $\left(\sigma^{2}{ }_{\mathrm{w}} / \sigma^{2}{ }_{\mathrm{B}}\right)$ for accelerometer indices are reported in Table II. Both crude and adjusted variability ratios were far higher for hourly accelerometer variables compared with daily accelerometer variables. After adjustment for residence and sex, the variability ratios increased for both 14-hour and 4day accelerometer variables by $34-313 \%$, although the increases were greater for the 14-hour period compared with the 4-day period. Adjustment for residence and sex reduced the inter- or between-subject variability $\left(\sigma_{\mathrm{B}}^{2}\right)$, thereby increasing the ratio. The higher ratios mean that more periods of objective physical activity monitoring would be required to reliably predict physical activity, especially so for hour-by-hour accelerometer indices.
Total variance in each of the 14-hour accelerometer indices was higher in the urban sample, suggesting that the distribution of activity and inactivity levels in the urban sample was more heterogeneous compared with the rural sample (Table III). For both groups intra-individual variability was the largest source of variance $(71-82 \%)$. The distribution of inter-individual and hour of day variability differed between the rural and urban group. In the rural group, hour of day variability was the second highest source of variance $(15-18 \%)$, followed by inter-individual variability (3 - 14\%). In contrast, for the urban group, inter-individual variability was the second highest source of variance (14-18\%), followed by hour of day variability (2 - 7\%).

Unlike the 14-hour accelerometer variability, total variance for the 4-day period was not consistently higher in the rural or urban group (Table IV). In the rural group, inter-individual variance (47 $-58 \%$ ) tended to be slightly higher than intra-individual variance (43-51\%), while day of week variability was lowest $(0-6.5 \%)$ of all sources of variance. For accelerometer counts and moderate$2+$ vigorous activity level, variance distribution in the urban group mirrored that of the rural group; $49-57 \%$ inter-individual, $44-51 \%$ intra-individual and $0-2 \%$ day of week. In contrast, the urban group intra-individual variance for inactivity and moderate-1 levels were high compared with inter-individual variance: $69-91 \%$ v. 8 - 31\%, respectively.

Attenuated reliability coefficients for 14-hour accelerometer indices were less than 0.8 and were lower in the rural group compared with the urban group (Table V). Hourly moderate$2+$ vigorous activity was the most reliable for both the rural and urban groups. The most unreliable accelerometer indices were the inactivity and moderate-1 levels in the rural group. Excluding the two lowest reliabilities, the attenuated reliability coefficients increased by 0.12 to 0.19 units after accounting for intra-individual variation, while the reliability coefficients for the inactivity and moderate- 1 indices increased by $\sim 0.23$ units after deattenuation. The difference between rural and urban reliability remained even after deattenuation of all the reliability coefficients. To achieve a reliability coefficient of 0.8 for hourly accelerometer variables in the urban group would require approximately 2 periods of 12-hour monitoring (24 hours). In contrast, approximately 4 - 11 periods of 12-hour monitoring (48 - 130 hours) would be required in the rural group. In both groups, moderate-2+vigorous activity required fewer hours of monitoring to reliably predict 1 hour of activity (19 - 24 hours) compared with other accelerometer indices.

The reliability of 4-day accelerometer indices was generally higher compared with the 14-hour accelerometer variables (Table VI). Attenuated reliability coefficients in both the rural and urban groups were nearly identical except for the low reliability coefficients for inactivity and moderate- 1 indices in the urban group. The values of 8 of the 10 attenuated reliability coefficients increased by $0.08-0.10$ units after accounting for the intraindividual variation. The effect of deattenuation was not greater in the rural group (mean difference $=0.10$ units) or the urban group (mean difference $=0.09$ units) for 8 of the 10 reliability coefficients. Because of the higher intra-individual variation in the inactivity and moderate-1 activity indices of the urban group, the attenuated reliability coefficients increased by 0.16 to 0.48 units. In the rural group, at least 5 days of monitoring would be required to reliably predict one day of activity or inactivity. However, in the urban group, to reliably predict one day of inactivity, moderate-1 activity and moderate-2+vigorous activity would require 9, 44 and 4 days of monitoring, respectively. 


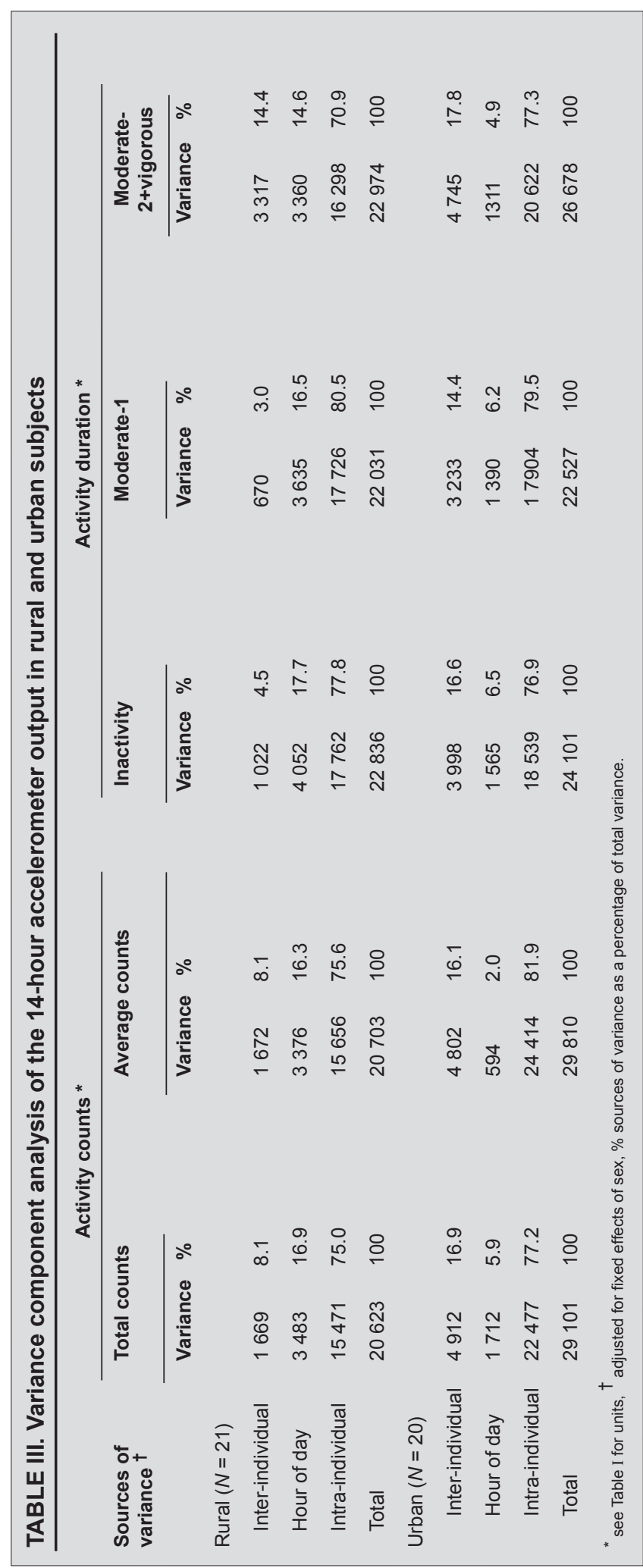

\section{Discussion}

This study is novel for two reasons. It is the first analysis that has reported on the reliability of objectively monitored physical activity in a South African setting. It is also the first analysis that has investigated the distribution of variance for any physical activity measure in a South African sample. The principal findings of this analysis were firstly that the distribution of variance differed depending on the sampling period. For the 4-day sampling period, between- or inter-subject variability, which represents true differences in physical activity indices between subjects, was at least as large as within- or intra-individual variability (behavioural variability), while day of week accounted for little of the variance $(<7 \%)$. In contrast, for the 14-hour monitoring period, intra-individual variation accounted for more than $70 \%$ of the variance, while hour of day and inter-individual variation accounted for the remaining variance. Secondly, irrespective of the monitoring period (14-hour or 4-day), total counts, average counts and moderate-2+vigorous activity tended to be the most reliable measures requiring the fewest number of monitoring periods. Thirdly, adjustment for basic demographic factors such as residence and sex prevents the under-estimation of monitoring days required so that reliable estimates of physical activity volumes and patterns can be obtained.

The authors are not aware of any other analysis investigating the reliability and variance distribution of accelerometry data collected in adult populations over monitoring periods shorter than a day. The results from the 14-hour monitoring period of the present study show that a reversal in variance distribution occurs in comparison to the 4-day period; intra-individual variance > inter-individual variance. Moreover, the relative contributions of the inter-individual variance and hour of day variance to the total variance were contrasted in the two residence-defined groups. This can be explained by the fact that the physical activity patterns in the rural group show relatively large changes over the course of the 14 hours, ranging from physical inactivity in the morning to being physically active during the working day, which is interspersed with breaks (tea, lunch), and back again to physically inactive levels during the late afternoon and evenings. This type of hourly activity pattern was quite homogenous throughout the rural group such that inter-individual variance was lower. In contrast, the activity patterns of the urban group tended to remain relatively constant over the period of the 14 hours, although this could differ between individuals, which explains the higher inter-individual variance in this group. It is likely then that similar investigations of hourly physical activity patterns in different samples will yield variance distributions that are in accord with the particular activity demands required of those samples. Importantly, the number of periods required to reliably estimate physical activity volumes and patterns will differ from sample to sample, particularly over shorter monitoring periods where variance contrasts between groups can be large. The greater intra-individual variance in the 14-hour monitoring period, although in accord with the variance distribution in questionnaire-based physical activity assessment cannot be because of factors related to the imprecision of measurement found in non-objective physical activity assessment. ${ }^{17}$ Rather, the greater intra-individual variance could be due to the natural variation in physical activity behaviour from hour to hour.

The results for the 4-day monitoring period are generally in agreement with data from North America in that inter-individual variation accounted for most of the variation. ${ }^{15}$ Matthews et al. examined accelerometry data collected from 92 adults over a period of 21 consecutive days. ${ }^{15}$ They found inter-individual variation contributed the most to overall variance (55-60\%) followed by intra-individual variance $(30-45 \%)$ and day of the week variance (1- $8 \%$ ). The number of days required to achieve $80 \%$ reliability for estimating activity counts and moderate$2+$ vigorous activity was $3-4$ day, ${ }^{15}$ which is in agreement with the present results of $4-5$ days. Moreover, the North American data also found that estimating physical inactivity was more 


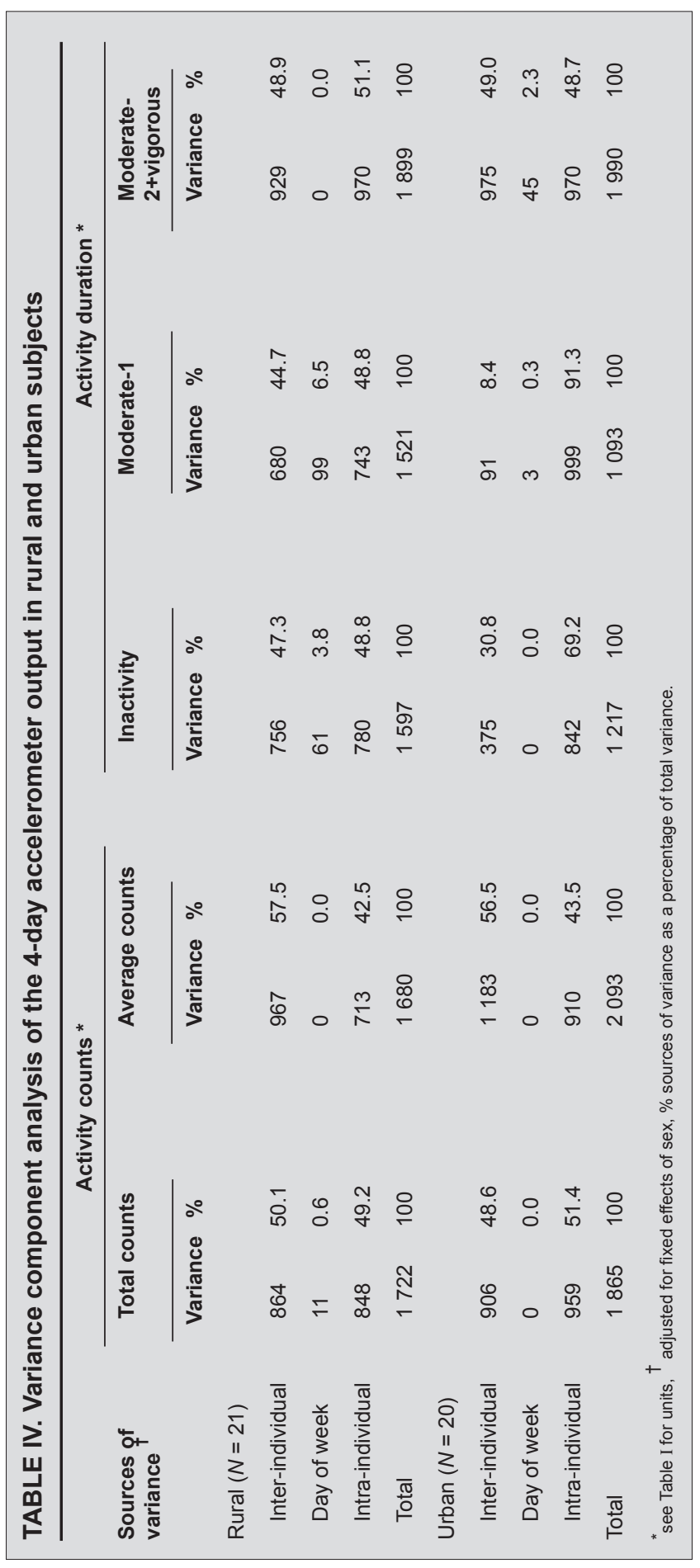

unreliable requiring more days of monitoring compared to most of the physical activity indices ( 7 days) and is in agreement with our finding of 5 - 10 days in the present results. The difference between inter-individual and intra-individual variance in the present study was not as pronounced as found by Matthews et al. ${ }^{15}$ but is still quite different to the variance distribution found in questionnaire-based physical activity assessment (50 - 60\% intraindividual, $20-30 \%$ inter-individual). ${ }^{18}$ It has been suggested that the differences in variance distribution between objective and self-reported physical activity assessment may be due to factors such as precision of objective measuring instruments, the ability of objective measuring instruments to detect common, light intensity activities and the level of variability present in selfreport instruments. ${ }^{15}$
The results of the present investigation also accord with the prediction of Matthews et al. that because of the differences between study samples in terms of variance distribution, each study sample would have different sampling requirements. ${ }^{15}$ The present results have shown general agreement in that interindividual variance is at least as great as intra-individual variance. Specific differences have also been shown in the present study, in that the differences between inter-individual and intra-individual variances are not as pronounced as those found by others. ${ }^{15}$ Consequently, the number of days required to reliably estimate the various physical activity and inactivity indices differ from that proposed by others. ${ }^{15}$ The predicted qualitative differences between our results from those of others ${ }^{15}$ would appear to add further support the validity of the present analysis.

It would certainly be profitable to analyse the larger South African accelerometry dataset that was part of the IPAQ validation study, especially because of the heterogeneity of the South African population. This dataset contains accelerometry data from a relatively large sample of subjects $(N>100)$ differing in age, body composition, education level, ethnicity, fitness, language, residence, sex, and socio-economic status. The examination of the reliability and the variance distribution of this dataset would provide valuable information for the South African researcher. There is a lack of published information regarding the number of days of objectively monitored physical activity that would be required to reliably estimate objectively measured physical activity levels and patterns in specific sub-sections of the South African population.

The strength of the present study is firstly the uniqueness of the analysis within a South African context, which will hopefully provide further motivation and impetus for more analyses of this kind. Secondly, this analysis provides reliability and variance estimates for a South African sample of a particular ethnicity,

TABLE V. Intraclass correlation reliability analysis of 14-hour accelerometer output indices in rural and urban subjects

\begin{tabular}{|c|c|c|c|}
\hline \multirow[b]{2}{*}{ Variables * } & \multicolumn{2}{|c|}{$\begin{array}{l}\text { Reliability } \\
\text { (ICC) }\end{array}$} & \multirow{2}{*}{$\begin{array}{l}\text { Required number } \\
\text { of hours to achieve } \\
\text { a reliability of } 0.8\end{array}$} \\
\hline & 14 hours $^{\dagger}$ & 1 hour & \\
\hline \multicolumn{4}{|l|}{ Rural $(N=21)$} \\
\hline Total counts & $0.55(0.74)$ & 0.08 & 45.4 \\
\hline Average counts & $0.55(0.74)$ & 0.08 & 45.5 \\
\hline Inactivity & $0.40(0.63)$ & 0.04 & 85.4 \\
\hline Moderate-1 & $0.31(0.55)^{\ddagger}$ & 0.03 & 127.6 \\
\hline $\begin{array}{l}\text { Moderate- } \\
2+\text { vigorous }\end{array}$ & $0.70(0.84)$ & 0.14 & 23.7 \\
\hline \multicolumn{4}{|l|}{ Urban $(N=20)$} \\
\hline Total counts & $0.74(0.86)$ & 0.17 & 19.7 \\
\hline Average counts & $0.73(0.85)$ & 0.16 & 20.8 \\
\hline Inactivity & $0.74(0.86)$ & 0.17 & 20.1 \\
\hline Moderate-1 & $0.70(0.84)$ & 0.14 & 23.9 \\
\hline $\begin{array}{l}\text { Moderate- } \\
2+\text { vigorous }\end{array}$ & $0.75(0.87)$ & 0.18 & 18.5 \\
\hline
\end{tabular}


TABLE VI. Intraclass correlation reliability analysis of 4-day accelerometer output indices in rural and urban subjects

\begin{tabular}{|c|c|c|c|}
\hline \multirow[b]{2}{*}{ Variables * } & \multicolumn{2}{|c|}{$\begin{array}{l}\text { Reliability } \\
\text { (ICC) }\end{array}$} & \multirow{2}{*}{$\begin{array}{l}\text { Required number } \\
\text { of days toachieve } \\
\text { a reliability of } 0.8\end{array}$} \\
\hline & 4 days $^{\dagger}$ & 1 day & \\
\hline \multicolumn{4}{|l|}{ Rural $(N=21)$} \\
\hline Total counts & $0.80(0.89)$ & 0.50 & 4.0 \\
\hline Average counts & $0.84(0.92)$ & 0.58 & 3.0 \\
\hline Inactivity & $0.78(0.88)$ & 0.47 & 4.5 \\
\hline Moderate-1 & $0.76(0.87)$ & 0.45 & 5.0 \\
\hline $\begin{array}{l}\text { Moderate- } \\
2+\text { vigorous }\end{array}$ & $0.79(0.89)$ & 0.49 & 4.2 \\
\hline \multicolumn{4}{|l|}{ Urban $(N=20)$} \\
\hline Total counts & $0.79(0.89)$ & 0.49 & 4.2 \\
\hline Average counts & $0.84(0.92)$ & 0.57 & 3.1 \\
\hline Inactivity & $0.64(0.80)$ & 0.31 & 9.0 \\
\hline Moderate-1 & $0.27(0.75) \ddagger$ & 0.08 & 43.8 \\
\hline $\begin{array}{l}\text { Moderate- } \\
2+\text { vigorous }\end{array}$ & $0.79(0.89)$ & 0.49 & 4.2 \\
\hline
\end{tabular}

language and residence status. The weakness of this study is the relatively low number of subjects. However, the fact that our results concur generally and differ specifically, as expected, with the results of a similar, larger analysis, ${ }^{15}$ suggests that despite the relatively small sample size the results of the present analysis are valid. It should also be noted that some of the stratified random effects analyses performed by Matthews et al. were done on sample sizes as low as $14 .^{15}$

In conclusion, this analysis has provided quantitative estimates of the reliability and distribution of variance of objectively measured physical activity measures in a specific ethnic and language group, over two monitoring periods (14hour and 4-day). Further analyses using larger sample sizes and in different sub-sections of the South African population are required for both questionnaire-based and objectively measured physical activity indices.

\section{Acknowledgements}

We are indebted to the study participants and field workers for their sustained and friendly co-operation, and to Mr Trevor Phillips who kindly arranged access to the forestry and factory staff at Steven's Lumber Mills. The Research Development and Administration Division of the University of Limpopo (Turfloop Campus) and the Research Capacity Development Group of the Medical Research Council of South Africa supported this study.

\section{REFERENCES}

1. Altman DG. Practical Statistics for Medical Research. Boca Raton: Chapman and Hall/CRC, 1999.

2. Bohlmann IM, Mackinnon S, Kruger $S$ et al. Is the International Physical Activity Questionnaire (IPAQ) valid and reliable in the South African population? Med Sci Sports Exerc 2001; 33: S119.
3. Coleman KJ, Epstein LH. Application of generalizability theory to measurement of activity in males who are not regularly active: a preliminary report. Res Q Exerc Sport 1998; 69: 58-63.

4. Cook I, Lambert EV. Validity and reliability of the International Physical Activity Questionnaire in Northern Sotho-speaking Africans. JEMDSA 2002; 7: S36.

5. Craig CL, Marshall AL, Sjostrom M, et al. International Physical Activity Questionnaire: 12-country reliability and validity. Med Sci Sports Exerc 2003; 35: 1381-95.

6. de Mast J, van Wieringen W. Measurement system analysis for bounded ordinal data. Qual Reliab Engng Int 2004; 20: 383-95.

7. Dishman RK, Washburn RA, Heath GW. Physical Activity Epidemiology. Champaign, IL: Human Kinetics, 2004.

8. DuRant $\mathrm{RH}$, Baranowski T, Davis $\mathrm{H}$, et al. Reliability and variability of indicators of heart-rate monitoring in children. Med Sci Sports Exerc 1993; 25: 389-95.

9. DuRant RH, Baranowski T, Davis H, Thompson WO, Puhl J, Greaves KA, Rhodes T. Reliability and variability of heart rate monitoring in 3-, 4-, or 5-yrold children. Med Sci Sports Exerc 1992; 24: 265-71.

10. Gretebeck RJ, Montoye HJ. Variability of some objective measures of physical activity. Med Sci Sports Exerc 1992; 24: 1167-72.

11. Janz KF, Witt J, Mahoney LT. The stability of children's physical activity as measured by accelerometry and self-report. Med Sci Sports Exerc 1995; 27 : 1326-32.

12. Kruger HS, Venter CS, Steyn HS. A standardised physical activity questionnaire for a population in transition: the THUSA study. Afr J Phys Health Educ Recreat Dance 2000; 6: 54-64.

13. Lambert EV, Bohlmann I, Kolbe-Alexander T. 'Be Active' - Physical activity for health in South Africa. S Afr J Clin Nutr 2001; 14: S12-S16.

14. Levin S, David R, Ainsworth BE, Richardson MT, Leon AS. Intra-individual variation and estimates of usual physical activity. Ann Epidemiol 1999; 9: 481-8.

15. Matthews CE, Ainsworth BE, Thompson RW, Bassett DR. Sources of variance in daily physical activity levels as measured by an accelerometer. Med Sci Sports Exerc 2002; 34: 1376-81.

16. Matthews CE, Freedson PS, Hebert JR, Stanek EJ, Merriam PA, Ockene IS. Comparing physical activity assessment methods in the Seasonal Variation of Blood Cholesterol Study. Med Sci Sports Exerc 2000; 32: 976-84.

17. Matthews CE, Freedson PS, Hebert JR, et al. Seasonal variation in household, occupational, and leisure time physical activity: longitudinal analyses from the Seasonal Variation of Blood Cholesterol Study. Am J Epidemiol 2001; 153: 172-83.

18. Matthews CE, Hebert JR, Freedson PS, et al. Sources of variance in daily physical activity levels in the Seasonal Variation of Blood Cholesterol Study. Am J Epidemiol 2001; 153: 987-95.

19. McGraw KO, Wong SP. Forming inferences about some intraclass correlation coefficients. Psychol Methods 1996; 1: 30-46.

20. Montoye HJ, Kemper HCG, Saris WHM, Washburn RA. Measuring Physical Activity and Energy Expenditure. Champaign, IL: Human Kinetics, 1996.

21. Murray DM, Catellier DJ, Hannan PJ, et al. School-level intraclass correlation for physical activity in adolescent girls. Med Sci Sports Exerc 2004; 36: 876-82.

22. Nyambose J, Koski KG, Tucker KL. High intra/interindividual variance ratios for energy and nutrient intakes of pregnant women in rural Malawi show that many days are required to estimate usual intake. J Nutr 2002; 132: 131318.

23. Palaniappan U, Cue RI, Payette H, Gray-Donald K. Implications of day-today variability on measurements of usual food and nutrient intakes. J Nutr 2003; 133: 232-5

24. Treuth MS, Sherwood NE, Butte NF, et al. Validity and reliability of activity measures in African-American girls for GEMS. Med Sci Sports Exerc 2003; 35: 532-9.

25. Trost SG, Pate RR, Freedson PS, Sallis JF, Taylor WC. Using objective physical activity measures with youth: how many days of monitoring are needed? Med Sci Sports Exerc 2000; 32: 426-31.

26. Tudor-Locke C, Burkett L, Reis JP, Ainsworth BE, Macera CA, Wilson DK. How many days of pedometer monitoring predict weekly physical activity in adults? Prev Med 2005; 40: 293-8.

27. Vincent SD, Pangrazi RP. An examination of the activity patterns of elementary school children. Pediatr Exerc Sci 2002; 14: 432-41.

28. Welk GJ. Physical Activity Assessments for Health-Related Research. Champaign, IL: Human Kinetics, 2002.

29. Willett WC. Nature of variation in the diet. In: MacMahon B, ed. Nutritional Epidemiology: Monographs in Epidemiology and Biostatistics, vol. 15. New York: Oxford University Press, 1990: 34-51. 